\title{
A imagem de Blumenau no Instagram: um estudo sobre destino turístico em redes sociais usando equações estruturais
}

The Blumenau image in Instagram: a study on tourist destination in networks using structural equation

La imagen de Blumenau en Instagram: un estudio sobre el destino turístico en redes sociales usando ecuaciones estructurales

http://dx.doi.org/10.18472/cvt.16n1.2016.1045

Sérgio Luiz do Amaral Moretti < luiz.amaral@anhembimorumbi.edu.br >

Professor do Programa de Hospitalidade da Universidade Anhembi Morumbi (UAM), São Paulo, SP, Brasil.

Bruno Jahn Bertoli < brunobertoli.pp@gmail.com >

Bacharel em Comunicação Social com Habilitação em Publicidade e Propaganda pela Universidade Regional de Blumenau (Furb), Blumenau, SC, Brasil.

Fabrícia Durieux Zucco < fabriciazucco@hotmail.com >

Professora do Programa de Mestrado e Doutorado em Turismo da Universidade Vale do Itajaí (Univali), Balneário Camburiú, SC, Brasil, e professora de Comunicação da Universidade Regional de Blumenau (Furb), Blumenau, SC, Brasil.

CRONOLOGIA DO PROCESSO EDITORIAL

Recebimento do artigo: 06-mar-2014

Aceite: 20 -fev-2016

FORMATO PARA CITAÇÃO DESTE ARTIGO

MORETTI, S. L. A.; BERTOLI, B. J.; ZUCCO, F. D. A imagem de Blumenau no Instagram: um estudo sobre destino turístico em redes sociais usando equações estruturais. Caderno Virtual de Turismo. Rio de Janeiro, v. 16 n. 1, p. 126-140, abr. 2016.

$$
\text { REALIZAÇÃO }
$$

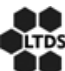

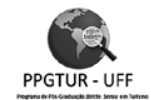

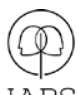

APOIO INSTITUCIONAL

EDIÇÃO

PATROCÍNIO 


\section{RESUMO}

A imagem do destino turístico é fator de decisão crucial para seus visitantes e construída com forte influência das suas fontes de informação. $\mathrm{Na}$ atualidade, as principais fontes são encontradas na internet permitindo aliar mídias sociais e fotografia digital. Nesse cenário, o presente trabalho tem como objetivo analisar a representação da imagem de destino da cidade de Blumenau (SC) no Instagram, uma das mídias sociais que mais crescem no Brasil. Trata-se de uma pesquisa exploratória e quantitativa, cuja coleta de dados foi realizada entre os dias 6 de março e 18 de abril de 2014, por meio de um software específico para monitoramento de mídias sociais. Foram analisadas 1000 imagens marcadas com a hashtag \#Blumenau. A análise contou com procedimentos estatísticos de Alfa de Cronbach, Correlação de Spearman e Modelagem de Equação Estrutural. Os principais resultados apontam que as fotografias publicadas têm forte relação com Aspectos Gerais, Eventos, Lazer, Gastronomia e Arquitetura Típica.

Palavras-chave: Imagem de destino. Turismo. Mídias Sociais. Instagram.

\section{ABSTRACT}

The image of the tourist destination is crucial deciding factor for the visitors and built with strong influence of their sources of information. Currently, the main sources are found on the Internet allowing to combine social media and digital photography. In this scenario, the present study aims to analyze the representation of the target image of the city of Blumenau (SC) on Instagram, one of the fastest growing social media in Brazil. This is an exploratory and quantitative research, which data collection was held between March 6 and April 18,2014 , through a specific software to monitor social media. 1000 images tagged with the hashtag \#Blumenau were analyzed. The analysis included statistical procedures of Cronbach's alpha, Spearman correlation and Structural Equation Modeling. The main results indicate that the published photographs have strong relationship with Overview, Events, Leisure, Gastronomy and typical architecture.

Keywords: Target image. Tourism. Social Media. Instagram.

\section{RESUMEN}

La imagen del destino turístico es crucial factor decisivo para sus visitantes y construido con una fuerte influencia de sus fuentes de información. En la actualidad, las principales fuentes se encuentran en Internet que permite combinar los medios de comunicación social y la fotografía digital. En este escenario, el presente estudio tiene como objetivo analizar la representación de la imagen de destino de la ciudad de Blumenau (SC) en Instagram, una de las de más rápido crecimiento en medios sociales en Brasil. Se trata de una investigación exploratoria y cuantitativa, que la recolección de datos se llevó a cabo entre el 06 de marzo y 18 de abril de 2014, a través de un software específico para controlar los medios de comunicación social. Se analizaron 1.000 imágenes etiquetadas con el hashtag \#Blumenau. El análisis incluyó procedimientos estadísticos de alfa de Cronbach, correlación de Spearman y modelos de ecuaciones estructurales. Los principales resultados indican que las fotografías publicadas tienen fuerte relación con Overview, Eventos, Ocio, Gastronomía y la arquitectura típica.

Palavras clave: Imagen de destino. Turismo. Medios de Comunicación Social. Instagram. 


\section{Introdução}

Atualmente, usuários publicam fotos dos lugares onde vivem e de viagens instantaneamente em seus perfis sociais, como Facebook, Instagram e Flickr. Essas fotografias se tornaram ferramentas fundamentais na criação e promoção da imagem do destino. Elas não somente demonstram visualmente os locais como, também, comunicam seus atributos, características, ideais e valores (DOPRA; TRZASKOS; BAUM, 2011).

O campo da imagem de destinos turísticos tem uma vasta literatura destacando-se as contribuições de Baloglu e McCleary (1999), Chagas (2008, 2009), Figueirêdo e Mayer (2010), Pérez-Nebra e Torres (2010), Chagas, Dantas e Fernandes (2010) e Brea e Cardoso (2011). No que tange à influência da internet aliada às mídias sociais é nítida no campo do turismo; Medina e Werner (2007), Marujo (2008), Jacobsen e Munar (2012), Vieira (2012), Boley, Magnini e Tuten (2013) e Perinotto (2013) abordam o assunto sob diferentes perspectivas.

A cidade de Blumenau apresenta alto potencial turístico e atrai turistas de várias regiões do Brasil e até do mundo pelas suas belezas naturais, eventos de caráter nacional e festas populares. A cidade conta ainda com infraestrutura preparada quando se fala em hotelaria e restaurantes, além de vários roteiros turísticos, cervejarias e centros comerciais.

O presente estudo tem o principal objetivo de identificar a representação da imagem de destino da cidade de Blumenau no Instagram, analisando quais são as implicações para a gestão da imagem de destino da cidade. Em março de 2014, o blog do Instagram anunciou que a ferramenta havia ultrapassado a marca de 200 milhões de usuários ativos por mês no mundo. São cerca de 1,6 bilhão de fotos curtidas e 60 milhões de fotos postadas diariamente.

Este artigo é parte de um projeto desenvolvido com o Conselho Nacional de Desenvolvimento Científico e Tecnológico - CNPq, chamada 14/2014, que estuda um modelo de referência para a análise da imagem de destino turístico projetada nas mídias sociais virtuais.

O artigo está dividido nas seguintes seções: fundamentação teórica, métodos utilizados na pesquisa, os principais resultados e discussão e, por fim, as considerações finais.

\section{Revisão da literatura}

A imagem dos destinos turísticos está comumente associada aos seus atributos naturais e culturais, além das vantagens que oferece em relação aos demais destinos (SMITH; AMORIM; SOARES, 2013). Nesse sentido, Chagas (2009) destaca três características básicas da imagem de destino: 1) a subjetividade; 2) ser tomada como realidade, mesmo quando dela se difere e, 3) a dinamicidade. A primeira característica se refere ao aspecto individualista da análise da imagem, pois cada observador atribui significado ao objeto observado, de acordo com seu lado afetivo, sua formação ideológica, cultural, etc., podendo, assim, o mesmo objeto ter o número de imagens igual ao número de sujeitos indagados sobre ela (CHAGAS, 2009, p. 05). A maioria dos pesquisadores concorda com a existência de três componentes distintos hierarquicamente relacionados: cognitivo, afetivo e global (BREA; CARDOSO, 2011).

Perinotto (2013, p. 01) conceitua dois importantes aspectos da formação de imagem, por meio das abordagens utilizadas na comunicação: 1) a imagem mental, ou seja, todas as imagens que a mente produz 
a partir de experiências vividas, das mensagens recebidas e assimiladas bem como através da compreensão do mundo; e 2) a imagem que serve como suporte para a comunicação, por meio da fotografia, televisão e cinema.

Pesquisa recente do Ibope constatou que a internet já é a primeira fonte de informações gerais de quase metade dos brasileiros. O resultado apontou que $47 \%$ dos entrevistados tem a internet como sua forma preferencial de ter acesso a notícias. O percentual está acima da média mundial, que é de 45\% (EXAME, 2014).

Marujo (2008) aponta que o desenvolvimento da internet deu origem a novos destinos turísticos, além do aumento da competitividade entre esses destinos, que se promovem diariamente. Vieira (2012) comenta que o turismo e a internet, juntos, compõem uma estrutura de trabalho conjunto, pois tudo se torna mais fácil e instantâneo para quem procura serviços de apoio. Para De Lucca Filho (2005), "a internet fornece acesso imediato a informações relevantes sobre os destinos em todo o mundo, com maior variedade e profundidade do que era possível antes, e permite fazer reservas de forma rápida e fácil” (p. 60).

Um estudo da comScore (2012) constatou que, em julho de 2012, 16,5 milhões de brasileiros visitaram sites de viagens. O levantamento aponta um aumento de $18 \%$ em relação a 2011, um recorde de brasileiros que utilizaram a internet para planejarem as suas viagens.

O site de viagens TripAdvisor (2013) realizou uma pesquisa com aproximadamente 20 mil turistas de 26 países, em junho e julho de 2012, dos quais 890 brasileiros compõem a amostra do estudo. Os resultados mostram que $61 \%$ dos viajantes mundiais e $74 \%$ dos brasileiros usam as redes sociais quando estão viajando. Entre os entrevistados, quase 30\% disseram que atualizam seus perfis nas redes sociais diariamente durante a viagem, e, no caso dos brasileiros, esse número sobe para $42 \%$. Outros dados interessantes revelados pela pesquisa: $72 \%$ dos entrevistados utilizam as redes sociais para obter recomendações, 67\% para ver imagens e vídeos de onde querem visitar, 60\% para encontrar inspiração para o que fazer e ver no destino e $45 \%$ para buscar ofertas de pacotes.

Aproximadamente $89 \%$ dos turistas tiram fotos em suas viagens e $41 \%$ postam suas fotos em redes sociais virtuais (BOLEY; MAGNINI; TUTEN, 2013). Esse acúmulo de fotografias publicadas na internet dá ao consumidor de turismo a oportunidade de conhecer virtualmente os destinos que pretende visitar. A partir do conteúdo publicado, usuários no mundo todo podem realizar buscas e avaliar imagens antes de decidirem o destino de suas viagens. Nos dias atuais, os turistas atuam como construtores de imagens turísticas (DONAIRE; GALÍ, 2011).

As fotografias são ferramentas fundamentais na criação e promoção da imagem do destino. Elas não somente demonstram visualmente o destino, mas também comunicam os atributos, as características, os ideais e os valores que fazem parte dele (DOPRA; TRZASKOS; BAUM, 2011). A importância da fotografia para as experiências de viagens cresce com a popularidade das mídias sociais, que possibilitam ao turista publicar fotos de suas viagens instantaneamente em mídias sociais como Instagram, Facebook, Flickr e outros (BOLEY; MAGNINI; TUTEN, 2013).

Entre tantas mídias sociais existentes e utilizadas, destaca-se o Instagram, que tem como principal função o compartilhamento de fotos através de dispositivos móveis. Ele foi lançado em outubro de 2010 como uma rede social gratuita baseada no compartilhamento de fotos. Permite aos usuários cadastrados imediatamente tirar fotos, aplicar filtros e instantaneamente compartilhar suas fotos em seus perfis pessoais. 
Dados divulgados em março de 2014 pelo blog do Instagram afirmam que o site ultrapassou a marca de 200 milhões de usuários ativos por mês, um aumento de 50 milhões de usuários em seis meses, visto que atingiu 150 milhões em setembro de 2013. Em abril de 2014, o Portal R7 divulgou uma pesquisa da Nielsen que identificou que o Instagram já passou o Twitter em número de usuários ativos nos EUA.

A empresa Kindai, agência de comunicação digital especializada em mídias sociais e geração de conteúdo, realizou um estudo sobre a interação entre os usuários, influenciadores e marcas no Instagram na França. De acordo com o estudo, o turismo aparece como a indústria mais popular. Para $45 \%$ dos entrevistados, o turismo é a atividade mais interessante na rede social e $47 \%$ estiveram em um local por causa das fotos publicadas pelos seus amigos no Instagram (TOUR MAG, 2014).

\section{Métodos}

Trata-se de uma pesquisa exploratória de caráter quantitativo, procedimento necessário para que se tenha um panorama de como está representada a imagem de destino de Blumenau no Instagram. O indicado seria fazer um estudo anual, mas para isso seria necessário ativar um monitoramento em março de 2014 e dar continuidade a ele até março de 2015; proposta inviável, considerando o tempo de pesquisa disponível para o estudo. Desse modo, foram analisadas, de forma aleatória, 1000 imagens entre os dias 6 de março e 18 de abril de 2014.

O instrumento para a coleta de dados foi desenvolvido com base no estudo de Donaire e Galí (2011) que apresentou cinco itens para a categorização das fotografias analisadas: 1) Identificação, ou o elemento principal representado na imagem; 2) Categoria, ou o que se pretende analisar; 3) Período, momento histórico do elemento fotografado; 4) Zoom, ou o elemento fotografado - por completo, inserido em seu contexto ou panorâmica; e, por último, 5) Grau de Humanização, ou o elemento humano presente na fotografia.

Para fins deste estudo foram adaptados três dos itens acima: Categoria, Período e Grau de Humanização. A partir do item Categoria, buscou-se identificar os elementos presentes nas imagens publicadas. O item Período foi adaptado, para considerar o mês, dia do mês e dia da semana em que cada imagem foi publicada. O item Grau de Humanização foi adaptado para a mensuração da quantidade de pessoas existentes em cada uma das imagens.

Foram analisadas fotografias marcadas com a hashtag \#Blumenau, e para delimitar e filtrar imagens que não possuíam relação com moradores, turistas, ou com a cidade de Blumenau, utilizou-se um critério-filtro. Outro ponto avaliado em cada imagem foi o gênero do usuário, e as legendas das imagens foram avaliadas com objetivo de atribuir os critérios positivo ou negativo em relação à cidade de Blumenau.

A coleta das imagens foi realizada a partir do software Seekr Monitor - www.seekr.com.br, uma das ferramentas da empresa Seekr Gestão e Monitoramento em Mídias Sociais. As informações foram transferidas para uma planilha no Microsoft Office Excel 2007 e depois exportadas para o software SPSS, no qual foram realizados tratamentos estatísticos para a análise dos dados.

No que tange à categorização e análise de dados, utilizou-se como método a análise morfológica e de conteúdo, que, conforme Reis (2008), é uma técnica de pesquisa que visa identificar, descrever e classificar a forma e o teor de mensagens jornalísticas e publicitárias. 
Para verificar a confiabilidade e a consistência interna do construto, utilizou-se a análise do Alfa de Cronbach ou Coeficiente Alfa. Conforme Malhotra (2001), o Alfa de Cronbach varia entre 0 a 1, e, quanto mais próximo de 1 , maior o índice de confiabilidade do estudo. O construto utilizado neste trabalho alcançou o escore de 0,8909, considerado satisfatório. A partir dessa exposição e da validade dos dados de Cronbach, serão apresentados os resultados multivariados da pesquisa, com a aplicação de dois tratamentos estatísticos: Correlação de Spearman e Modelagem de Equação Estrutural (MEE).

\section{Principais resultados e discussão}

Conforme a amostra estipulada de 1000 imagens para a elaboração deste estudo, foram analisadas 500 imagens no mês de março e 500 imagens no mês de abril de 2014. O total de fotos relacionadas a Blumenau foi de 927 ou $92,7 \%$ do total.

Considerando a avaliação da cidade nas fotografias analisadas, 91,05\% apresentaram avaliações neutras. Esse índice mostra que é baixa a amostra de usuários que incluíram comentários positivos ou negativos da cidade em suas publicações. O Quadro 1 traz os resultados gerais de cada dimensão presente nas fotografias analisadas.

É possível verificar que Aspectos Gerais $(44,34 \%)$ foi a dimensão com maior frequência entre as fotografias analisadas. A razão disso é ter abrigado um número considerável de variáveis que não se encaixavam nas outras dimensões. Já os demais itens na ordem, Lazer, Gastronomia, Eventos e Arquitetura Típica são fortes características da cidade de Blumenau (PREFEITURA DE BLUMENAU, 2014) e serão destacadas a seguir.

\section{Quadro 1. Resultado das dimensões do construto}

\begin{tabular}{|c|c|c|}
\hline Dimensão & Frequência & $\%$ \\
\hline Arquitetura Típica & 53 & $5,72 \%$ \\
\hline Arquitetura Civil & 24 & $\mathbf{2 , 5 9 \%}$ \\
\hline Arquitetura Religiosa & 10 & $1,08 \%$ \\
\hline Elementos Urbanos & 66 & $7,12 \%$ \\
\hline Lazer & 102 & $11,00 \%$ \\
\hline Eventos & 68 & $7,34 \%$ \\
\hline Natureza & 19 & $2,05 \%$ \\
\hline Gastronomia & 101 & $10,90 \%$ \\
\hline Horizonte & 47 & $5,07 \%$ \\
\hline Fenômenos Meteorológicos & 10 & $1,08 \%$ \\
\hline Identidade Típica & 16 & $1,73 \%$ \\
\hline Aspectos Gerais & 411 & $44,34 \%$ \\
\hline Total & $\mathbf{9 2 7}$ & $\mathbf{1 0 0} \%$ \\
\hline
\end{tabular}

Fonte: Dados da pesquisa (2014)

De acordo com Manosso, Bizinelli e Gândara (2013) é importante analisar como os destinos são apresentados aos turistas, sejam estes potenciais ou reais. Entretanto, no Instagram, constatou-se que muitas das publicações marcadas com a hashtag \#Blumenau não tinham cunho turístico. Contudo, sua análise 
é relevante pelo fato de que essas fotos estão disponíveis na rede e são passíveis de consulta por possíveis turistas potenciais.

O Quadro 2 mostra a representatividade das fotografias que identificavam Arquitetura Típica, uma das características típicas da cidade de Blumenau. O Parque Vila Germânica obteve um resultado destacado, totalizando 36 imagens $-69,23 \%$ da dimensão e 3,88\% do total do construto. É um resultado satisfatório, considerando sua forte influência, já que lá acontecem as feiras, eventos culturais e festas típicas da cidade, como a tradicional Oktoberfest, e onde estão lojas de produtos regionais e artesanato típico, abertas ao público durante o ano todo (PARQUE VILA GERMÂNICA, 2014).

Quadro 2. Resultado descritivo por dimensão - Arquitetura Típica

\begin{tabular}{|c|c|c|c|c|}
\hline Dimensão & Variáveis & Frequência & \% dim. & \% construto \\
\hline \multirow{3}{*}{ Arquitetura Típica } & Vila Germânica & 36 & $\mathbf{6 9 , 2 3 \%}$ & $3,88 \%$ \\
\cline { 2 - 5 } & Prefeitura & 5 & $9,62 \%$ & $0,54 \%$ \\
\cline { 2 - 5 } & Castelinho Havan & 7 & $\mathbf{1 3 , 4 6 \%}$ & $0,76 \%$ \\
\cline { 2 - 5 } & Casa Enxaimel & 4 & $\mathbf{7 , 6 9 \%}$ & $0,43 \%$ \\
\hline & Total & $\mathbf{5 2}$ & $\mathbf{1 0 0} \%$ & $\mathbf{5 , 6 1} \%$ \\
\hline
\end{tabular}

Fonte: Dados da pesquisa (2014)

Na dimensão Lazer, o resultado foi considerável e representou $11,00 \%$ das fotografias analisadas. Um ponto a ser destacado é que Lazer é a dimensão com o maior número de variáveis do construto, totalizando 17 opções de lazer conforme o Quadro 3.

Quadro 3. Resultado descritivo por dimensão - Lazer

\begin{tabular}{|c|c|c|c|c|}
\hline Dimensão & Variáveis & Frequência & $\%$ dim. & $\%$ construto \\
\hline \multirow{16}{*}{ Lazer } & Bar & 11 & $10,78 \%$ & $1,19 \%$ \\
\hline & Restaurante & 7 & $6,86 \%$ & $0,76 \%$ \\
\hline & Museu & 1 & $0,98 \%$ & $0,11 \%$ \\
\hline & Estádio & 4 & $3,92 \%$ & $0,43 \%$ \\
\hline & Acampamento & 3 & $2,94 \%$ & $0,32 \%$ \\
\hline & $\begin{array}{c}\text { Museu da Cerveja/ } \\
\text { Biergarten }\end{array}$ & 7 & $6,86 \%$ & $0,76 \%$ \\
\hline & Shows & 11 & $10,78 \%$ & $1,19 \%$ \\
\hline & Piscina & 8 & $7,84 \%$ & $0,86 \%$ \\
\hline & Prática Esportiva & 21 & $20,59 \%$ & $2,27 \%$ \\
\hline & $\begin{array}{c}\text { Parque Ramiro } \\
\text { Ruediger }\end{array}$ & 5 & $4,90 \%$ & $0,54 \%$ \\
\hline & Prainha & 1 & $0,98 \%$ & $0,11 \%$ \\
\hline & Pesque e Pague & 2 & $1,96 \%$ & $0,22 \%$ \\
\hline & Cinema & 1 & $0,98 \%$ & $0,11 \%$ \\
\hline & Teatro & 1 & $0,98 \%$ & $0,11 \%$ \\
\hline & Balada & 11 & $10,78 \%$ & $1,19 \%$ \\
\hline & Shopping & 8 & $7,84 \%$ & $0,86 \%$ \\
\hline & Total & 102 & $100,00 \%$ & $11,00 \%$ \\
\hline
\end{tabular}

Fonte: Dados da pesquisa (2014) 
No Quadro 4 observa-se que o Festival da Cerveja, evento que aconteceu entre os dias 12 e 15 de março de 2014, no Parque Vila Germânica, apresentou o mais alto índice de imagens no estudo, totalizando 35,29\% da dimensão. Como afirmou Perinotto (2013), a imagem de destino turístico deve ser desenvolvida a partir de fotografias que representem as características da localidade, sejam paisagísticas, naturais, culturais, gastronômicas, artísticas e folclóricas, além da história, costumes e comportamentos da população.

No que diz respeito ao quesito sobre as características da localidade, vários pontos se mostraram presentes nas fotografias analisadas, com destaque para o Festival da Cerveja, a Osterdorf, o Parque Spitzkopf, Bares, Shows e Baladas. Outras opções de lazer e turismo em Blumenau se fizeram presentes nas fotografias analisadas, mas em representatividade bem inferior, como o Teatro Carlos Gomes, o Parque Ramiro Ruediger, Shoppings e Restaurantes.

Quadro 4. Resultado descritivo por dimensão - Eventos

\begin{tabular}{|c|c|c|c|c|}
\hline Dimensão & Variáveis & Frequência & $\%$ dim. & $\%$ construto \\
\hline \multirow{7}{*}{ Eventos } & Festival da Cerveja & 24 & $35,29 \%$ & $2,59 \%$ \\
\hline & Oktoberfest & 5 & $7,35 \%$ & $0,54 \%$ \\
\hline & Osterdorf & 14 & $20,59 \%$ & $1,51 \%$ \\
\hline & Protestos & 4 & $5,88 \%$ & $0,43 \%$ \\
\hline & Stammtisch & 1 & $1,47 \%$ & $0,11 \%$ \\
\hline & Outros & 20 & $29,41 \%$ & $2,16 \%$ \\
\hline & Total & 68 & $100,00 \%$ & $7,34 \%$ \\
\hline
\end{tabular}

Fonte: Dados da pesquisa (2014)

Conforme o Quadro 5, referente à dimensão Gastronomia, pode-se perceber a forte influência da variável Cerveja e Chopp, a única com resultado destacado e que concentrou $63,37 \%$ das fotos referentes à dimensão analisada.

Quadro 5. Resultado descritivo por dimensão - Gastronomia

\begin{tabular}{|c|c|c|c|c|}
\hline Dimensão & Variáveis & Frequência & \% dim. & \% construto \\
\hline \multirow{4}{*}{ Gastronomia } & Marreco & 2 & $1,98 \%$ & $0,22 \%$ \\
\cline { 2 - 5 } & Sushi & 6 & $5,94 \%$ & $0,65 \%$ \\
\cline { 2 - 5 } & Pizza & 1 & $0,99 \%$ & $0,11 \%$ \\
\cline { 2 - 5 } & Cerveja e Chopp & 64 & $63,37 \%$ & $6,90 \%$ \\
\cline { 2 - 5 } & Batata recheada & 4 & $3,96 \%$ & $0,43 \%$ \\
\cline { 2 - 5 } & Cupcake & 1 & $0,99 \%$ & $0,11 \%$ \\
\hline & Outros & 2 & $1,98 \%$ & $0,22 \%$ \\
\hline & Total & 101 & $\mathbf{1 0 0 , 0 0} \%$ & $\mathbf{1 0} \%$ \\
\hline
\end{tabular}

Fonte: Dados da pesquisa (2014)

Conforme os dados do Quadro 6, a dimensão Identidade Típica teve baixa amostra de fotografias. Entre as 16 fotos, a variável Fritz teve a maior frequência (43,75\%), com diferença de apenas uma foto para Fritz e Frida (37,50\%), onde ambos os trajes se faziam presentes nas fotos. Pode-se entender o baixo índice pela ausência de festas típicas na cidade no período em que se realizou a coleta de dados. 
Quadro 6 - Resultado descritivo por dimensão - Identidade Típica

\begin{tabular}{|c|c|c|c|c|}
\hline Dimensão & Variáveis & Frequência & \% dim. & \% construto \\
\hline \multirow{3}{*}{ Identidade Típica } & Fritz & 7 & $\mathbf{4 3 , 7 5 \%}$ & $0,76 \%$ \\
\cline { 2 - 5 } & Fritz e Frida & 6 & $37,50 \%$ & $0,65 \%$ \\
\cline { 2 - 5 } & Frida & 3 & $\mathbf{1 8 , 7 5 \%}$ & $0,32 \%$ \\
\hline \multirow{2}{*}{} & Total & $\mathbf{1 6}$ & $\mathbf{1 0 0 , 0 0 \%}$ & $\mathbf{1 , 7 3 \%}$ \\
\hline
\end{tabular}

Fonte: Dados da pesquisa (2014)

O Quadro 7 mostra os resultados entre as variáveis e o gênero dos usuários que publicaram as fotografias analisadas. Observa-se que o gênero Feminino tem uma correlação moderada apenas com as variáveis Arquitetura Típica e Horizonte. Já o gênero Masculino apresentou correlação leve ou pequena com todas as variáveis do construto. $\mathrm{O}$ gênero Institucional resultou em uma correlação moderada com a variável Lazer, e, por fim, o gênero Não Identificado apresentou alta correlação com a variável Gastronomia.

Quadro 7 - Correlação de Spearman - Variáveis x Gênero

\begin{tabular}{|c|c|c|c|c|}
\hline \multirow{2}{*}{ Variáveis } & \multicolumn{4}{|c|}{ Gênero } \\
\cline { 2 - 5 } & Masculino & Feminino & Institucional & Não/Ident. \\
\hline Arq. Típica & 0,01545 & 0,52314 & 0,21860 & 0,13340 \\
\hline Arq. Civil & 0,33636 & 0,03058 & 0,18170 & 0,35720 \\
\hline Arq. Religiosa & 0,29091 & 0,02645 & 0,31110 & 0,01470 \\
\hline Elem. Urbanos & 0,31818 & 0,02893 & 0,20770 & 0,26860 \\
\hline Lazer & 0,39091 & 0,03554 & 0,59490 & 0,05370 \\
\hline Eventos & 0,25455 & 0,02314 & 0,37940 & 0,11370 \\
\hline Natureza & 0,26364 & 0,02397 & 0,12830 & 0,15350 \\
\hline Gastronomia & 0,14545 & 0,01322 & 0,12150 & 0,78420 \\
\hline Horizonte & 0,01027 & 0,50975 & 0,09090 & 0,53700 \\
\hline Fen. Meteor. & 0,10636 & 0,00967 & 0,13668 & 0,51273 \\
\hline Ident. Típica & 0,17273 & 0,01570 & 0,11626 & 0,55870 \\
\hline Aspec. Gerais & 0,06364 & 0,12397 & 0,09584 & 0,60467 \\
\hline
\end{tabular}

Fonte: Dados da pesquisa (2014)

O Quadro 8 apresenta os resultados das correlações entre as variáveis e a avaliação positiva ou negativa da cidade de Blumenau. No que se refere à Arquitetura Típica, as fotografias apresentam avaliações positivas da cidade, com correlação moderada. Já no item Arquitetura Civil, há correlação moderada com avaliações negativas. Quanto à Arquitetura Religiosa, o resultado aponta correlação moderada para avaliações positivas e negativas, e correlação quase imperceptível para avaliações neutras. 
Quadro 8 - Correlação de Spearman - Variáveis x Avaliação

\begin{tabular}{|c|c|c|c|}
\hline \multirow{2}{*}{ Variáveis } & \multicolumn{2}{|c|}{ Avaliação } & Neutra \\
\cline { 2 - 4 } & Positiva & Negativa & 0,79810 \\
\hline Arquitetura Típica & 0,69470 & 0,07830 & 0,01340 \\
\hline Arquitetura Civil & 0,55370 & 0,74950 & 0,09650 \\
\hline Arquitetura Religiosa & 0,61580 & 0,57760 & 0,71440 \\
\hline Elem. Urbanos & 0,01050 & 0,23220 & 0,16830 \\
\hline Lazer & 0,45900 & 0,70170 & 0,22200 \\
\hline Eventos & 0,05641 & 0,57240 & 0,05190 \\
\hline Natureza & 0,68550 & 0,59490 & 0,57140 \\
\hline Gastronomia & 0,07440 & 0,41480 & 0,26860 \\
\hline Horizonte & 0,42000 & 0,20770 & 0,05370 \\
\hline Fen. Meteor. & 0,31610 & 0,59490 & 0,11370 \\
\hline Identidade Típica & 0,27537 & 0,37940 & 0,15350 \\
\hline Aspectos Gerais & 0,23465 & 0,12830 & \\
\hline
\end{tabular}

Fonte: Dados da pesquisa (2014)

Referente às fotografias de Elementos Urbanos, o resultado aponta alta correlação com avaliações neutras. A variável Lazer aponta correlação quase imperceptível com avaliações neutras e alta correlação com avaliações negativas.

Sobre fotografias de Eventos, observa-se correlação quase imperceptível com avaliações positivas e correlação moderada com avaliações negativas. A variável Natureza apresentou correlação quase imperceptível com avaliações neutras e correlação moderada com avaliações positivas e negativas.

No que se refere à Gastronomia, o resultado aponta correlação quase imperceptível com avaliações positivas e correlação moderada com as demais avaliações. Fotografias de Horizonte apresentam correlação moderada com avaliações positivas. Já Fenômenos Meteorológicos resultaram em correlação moderada com avaliações negativas, resultado esperável por conta das fotografias referentes a Enxurradas.

Por meio da Correlação de Spearman, que mede a intensidade entre as variáveis, identificou-se que, entre as fotografias analisadas, há uma tendência maior de que as mulheres compartilhem fotos de Arquitetura Típica e Horizonte. Já os homens tendem a publicar fotos relacionadas à Arquitetura Civil e Lazer. O gênero Institucional (empresas e perfis representando blogs e produtos) apresentou maior correlação com as dimensões Eventos e Lazer, enquanto o gênero Não Identificado teve mais ligação com fotos relacionadas às dimensões Gastronomia e Aspectos Gerais.

Por meio dessa análise estatística, foi possível concluir que as fotos relacionadas à Arquitetura Típica, Arquitetura Religiosa e Natureza têm uma tendência em apresentar avaliações positivas em relação à cidade de Blumenau. No entanto, fotografias que se enquadram nas dimensões Fenômenos Meteorológicos e Lazer estão mais suscetíveis a concentrar avaliações negativas.

Para Hair et al. (2005, p. 34), a modelagem de equação estrutural "é uma técnica que permite separar relações para cada conjunto de variáveis dependentes". Ainda segundo os autores, essa técnica combina os aspectos da análise fatorial e a regressão linear, com o intuito de verificar estatisticamente as possíveis 
relações entre os construtos. Para este estudo, optou-se por adotar a estratégia de desenvolvimento de modelos, modelo que deve ser testado e aperfeiçoado por meio de seguidas modificações, com o intuito de melhorar as adequações e evitar vieses e erros diversos.

A Figura 1 mostra a Modelagem de Equação Estrutural adotada neste estudo. Pode-se verificar que algumas dimensões se demonstraram mais representativas que outras, ou seja, o escopo de imagem de destino é mais influenciado por algumas variáveis. As dimensões Eventos e Aspectos Gerais (ambas com 89\%) são mais representativas para o construto. A primeira variável pode ser explicada pelo forte impacto e pela quantidade de eventos que ocorrem na cidade, já a segunda, pela quantidade de variáveis que faziam parte da dimensão total. Outra explicação é o fato de que a dimensão Aspectos Gerais obteve o maior número de fotografias da pesquisa - somando um total de 411 fotos e $44,34 \%$ de toda a amostra.

A dimensão Lazer foi a segunda com maior índice de relacionamento com o construto, com 85\%. Essa dimensão apresentou o segundo lugar em número de fotografias analisadas. Já a dimensão Gastronomia ficou em terceira posição e apresentou um índice de relacionamento de $77 \%$. Sua representatividade dentro da amostra foi alta, com $10,90 \%$ de todas as fotos analisadas, sendo a terceira dimensão em nível de frequência no construto. Vale justificar que essas duas dimensões subsequentes podem ser explicadas pela frequência de postagens de fotografias em situações de entretenimento e ligadas à alimentação.

Figura 1. Modelagem da Equação Estrutura

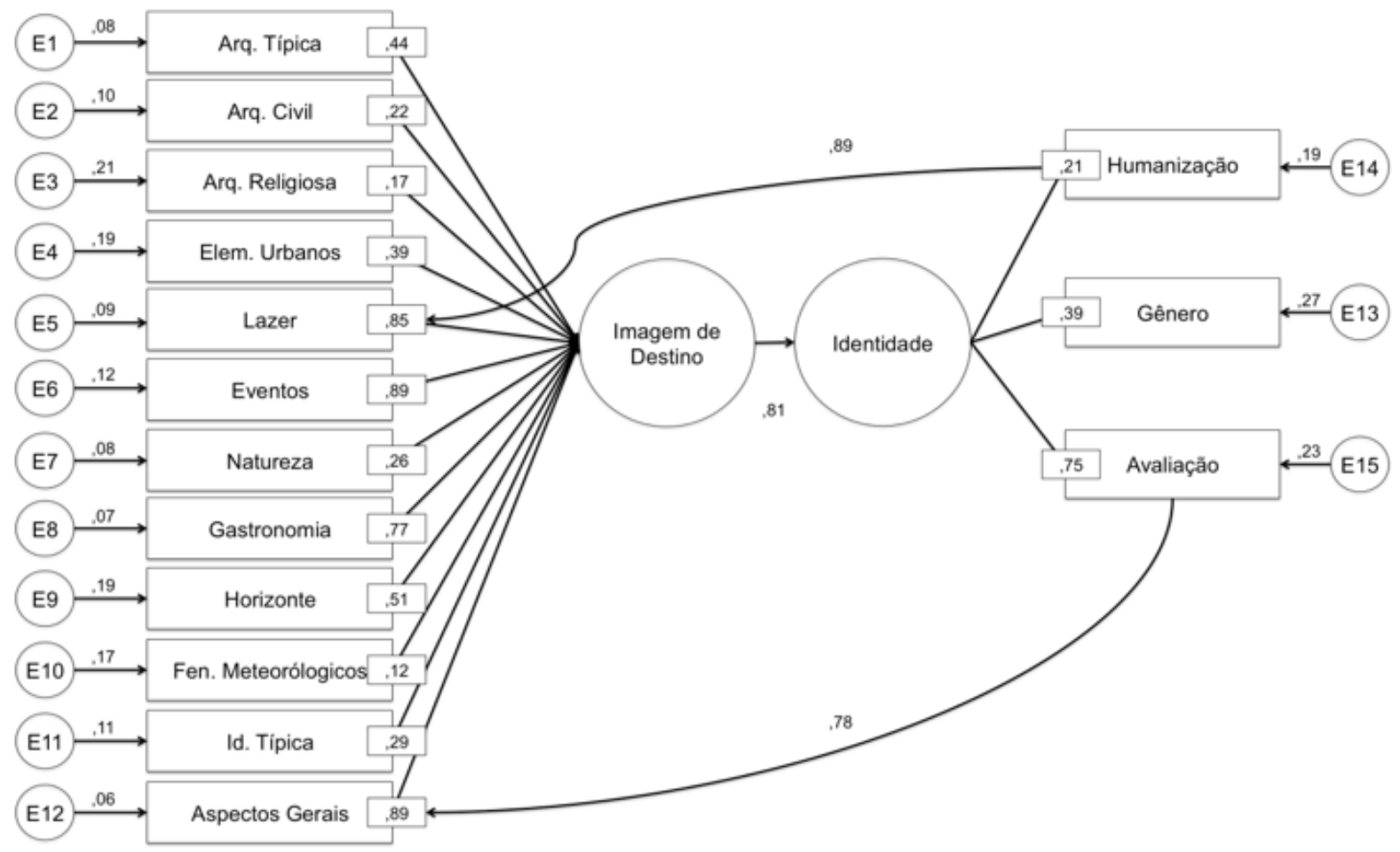

Fonte: Dados da pesquisa (2014)

Vale destacar que na Modelagem ocorreram dois pontos reversos: Humanização x Lazer (89\%) e Avaliação x Aspectos Gerais (78\%). O primeiro caminho de relacionamento aponta que, quanto mais as imagens eram ligadas a Lazer, maior era a quantidade de pessoas presentes nas fotografias. Na segunda 
situação, houve maior concentração de avaliação (positiva, negativa ou neutra) nas imagens da dimensão Aspectos Gerais.

Outro resultado de forte expressão foi a relação do construto com a dimensão Gastronomia, que apresentou índice de relacionamento de 77\%. Nessa dimensão, a variável que mais se destacou foi Cerveja e Chopp, que obteve $63,37 \%$ das fotos. Um fator que contribuiu para esse resultado foi o Festival Brasileiro da Cerveja, que aconteceu durante o período da coleta de dados, além da forte influência germânica da cidade de Blumenau.

Entre as fotografias que possuíam relação mais próxima com o turismo, destacou-se nos resultados a variável Vila Germânica, da dimensão Arquitetura Típica, com 69,23\% da amostra dessa dimensão e $3,88 \%$ de toda a amostra de fotografias analisadas, o que comprova o grande impacto que o local desempenha na promoção do lazer e do turismo em Blumenau.

A dimensão Arquitetura Típica apresentou correlação quase imperceptível com avaliações negativas. É importante que um local turístico esteja bem representado na internet e nas mídias sociais, pois, de acordo com Cruz, Camargo e Guzela (2007), os turistas decidem visitar ou não uma localidade em função da imagem que este destino turístico possui. Ainda segundo os autores, as fotografias geram expectativas e percepções de uma provável viagem.

\section{Considerações finais}

Neste estudo buscou-se analisar como a imagem de destino da cidade de Blumenau está representada no Instagram, uma mídia social que pode ser considerada como uma fonte de informação externa, apresenta forte adesão e recentemente ultrapassou a marca de 200 milhões de usuários no mundo.

Pode-se concluir que a imagem de destino de Blumenau representada no Instagram é positiva/atrativa. Esse tipo de imagem é aquela que favorece o destino e estimula a vinda de turistas ao local, afinal, apesar de não terem obtido a maior frequência entre as fotografias analisadas, vários espaços turísticos e de lazer e entretenimento da cidade de Blumenau estiveram presentes entre as fotografias analisadas.

Constatou-se que a maioria (91,05\%) apresentou legendas neutras em relação à cidade de Blumenau. Em contrapartida, as avaliações positivas (6,80\%) se sobressaíram em relação às negativas (2,16\%), ou seja, apesar da maioria das avaliações ter sido neutra, os aspectos positivos de Blumenau estão mais evidenciados do que os negativos no Instagram.

Os resultados mais expressivos da análise das dimensões estabelecidas foram Aspectos Gerais, Lazer, Gastronomia, Elementos Urbanos e Arquitetura Típica. Com relação à avaliação da cidade de Blumenau, a maioria das legendas das fotografias era neutra nesse quesito, entretanto, as avaliações positivas se mostraram maiores que as negativas. Constatou-se também que as fotografias relacionadas a Lazer possuem uma tendência em concentrar maior número de pessoas presentes.

No que se refere à representação da cultura germânica de Blumenau nas fotografias, a dimensão Identidade Típica apresentou baixo resultado entre as publicações, em decorrência da ausência de festas típicas na cidade no período de coleta de dados. Contudo, a dimensão Arquitetura Típica e a variável Cerveja e Chopp foram resultados de alta representatividade na análise dos dados. 
A principal limitação do estudo, como já mencionado, foi não ter conseguido o estudo de um ano inteiro que seguramente forneceria um melhor cenário. Por seu lado, a maior contribuição da pesquisa foi demonstrar o uso dos procedimentos de elaboração do instrumento de pesquisa e da coleta e análise de dados que servirá tanto para futuros pesquisadores quanto para os gestores ampliarem seus campos de estudo.

Desde que o presente estudo apresenta um recorte do Projeto CNPq Universal 14/2014 consideram-se oportunidades futuras para o aprofundamento da iniciativa iniciada com este artigo - a análise da imagem de destino da cidade de Blumenau, por meio de fotografias publicadas em outras mídias sociais, como o Flickr e o Facebook.

\section{Referências}

BALOGLU, S.; MCCLEARY, K. W. A model of destination image formation. Annals of Tourism Research, v. 26, n. 4, p. 868-897, 1999.

BOLEY, B. B.; MAGNINI, V. P.; TUTEN, T. L. Social media picture posting and souvenir purchasing behavior: Some initial findings. Tourism Management, v. 37, p. 27-30, 2013.

BRASIL. Ministério do Turismo. Internet é fonte para 1,87 milhão de turistas estrangeiros. Disponível em: 〈http://www.turismo.gov.br/turismo/noticias/todas_noticias/20130830-3.html〉. Acesso em: 03 abr. 2014, 2014.

Economia do turismo cresce no Brasil. Disponível em: 〈http://www.turismo.gov.br/turismo/ noticias/todas_noticias/20140417-1.html>. Acesso em: 21 mai. 2014, 2014.

BREA, J. A. F.; CARDOSO, L. Tourism Destination Image: reflexão sobre as principais investigações internacionais. Revista Cultura e Turismo, v. 5, n. 2, p. 05-18, 2013.

CHAGAS, M. M. Imagem de destinos turísticos: uma discussão teórica da literatura especializada. Revista Turismo Visão e Ação, v. 10, n. 3, p. 435-455, 2008.

- Formação da Imagem de Destinos Turísticos: uma discussão dos principais modelos internacionais. Caderno Virtual de Turismo, v. 9, n. 1, p. 117-127, 2009.

CHAGAS, M. M.; DANTAS, A. V. S.; FERNANDES, G. A. Modelos Teóricos de Pesquisa em Imagem de Destinos Turísticos: uma proposta de tipologia. VI Seminário de Pesquisa em Turismo do Mercosul. Universidade de Caxias do Sul, 2010.

COMSCORE. Record Number of Brazilians Turn to the Web for Planning and Booking Travel. Disponivel em: 〈http://www.comscore.com/Insights/Press_Releases/2012/8/Record_Number_of_Brazilians_ Turn_to_the_Web_for_Planning_and_Booking_Travel>. Acesso em: 15 mai. 2014, 2012.

CRUZ, L. L. D. et al. Redes sociais como estratégia de marketing turístico: o facebook e a região norte do Estado do Piauí - Brasil. Revista de Investigación em Turismo e Desarollo Local, v. 5, n. 13, 2012.

CRUZ, G.; CAMARGO, P.; GUZELA, M. Fotografia e suas interfaces para o desenvolvimento da imagem de um destino turístico. IX Seminário Internacional de Turismo - Ecoturismo e Turismo de Aventura. UNICENP - Curitiba, 2007. 
DE LUCCA F. V. Estudo do fluxo de informações em centros de informações turísticas de Santa Catarina: Programa Portais do Lazer. 134f. Dissertação (Mestrado em Ciência da Informação) - Programa de Pós-Graduação em Ciência da Informação, Universidade Federal de Santa Catarina, Florianópolis, 2005.

DONAIRE, J. A.; GALÍ, N. La imagen turística de Barcelona en la comunidad Flickr. Cuadernos de Turismo, v. 27 p. 291-303, 2011.

DROPA, A. F. N. S.; TRZASKOS, L.; BAUM, J. A imagem fotográfica como recurso de valorização cultural e seu uso pelo turismo: um estudo de caso da Colônia Sutil. II Seminário de Ciências Sociais Aplicadas da Faculdade Estadual de Ciências e Letras de Campos Mourão, 2011.

EXAME. Quase metade dos brasileiros se informam antes pela internet. Disponível em: <http:// exame.abril.com.br/tecnologia/noticias/quase-metade-dos-brasileiros-se-informam-antes-pelainternet>. Acesso em: 28 abr. 2014, 2014.

FIGUEIRÊDO, A. A.; MAYER, V. F. A Imagem dos Destinos Turísticos: a cidade de São Paulo sob o olhar de jovens do Rio de Janeiro. Turismo em Análise, v. 21, n. 3, p. 445-469, 2010.

G1. Instagram atinge marca de 200 milhões de usuários ativos por mês. Disponivel em: 〈http:// g1.globo.com/tecnologia/tem-um-aplicativo/noticia/2014/03/instagram-atinge-marca-de-200milhoes-de-usuarios-ativos-por-mes.html. Acesso em: 10 jun. 2014, 2014.

HAIR JR, J. F. et al. Análise Multivariada de Dados. 5. ed. Porto Alegre: Bookman, 2005.

IBOPE. Número de usuários de redes sociais ultrapassa 46 milhões de brasileiros. Disponível em: $\quad\langle$ http://www.ibope.com.br/pt-br/noticias/paginas/numero-de-usuarios-de-redes-sociaisultrapassa-46-milhoes-de-brasileiros.aspx>. Acesso em: 21 mai. 2014, 2014.

INSTAGRAM. Introducing vídeo on Instagram. Disponível em: <http://blog.instagram.com/ post/53448889009/video-on-instagram>. Acesso em: 27 mai. 2014, 2014.

JACOBSEN, J. K. S.; MUNAR, A. M. Tourist information search and destination choice in a digital age. Tourism Management Perspectives, v. 1, p. 39-47, 2012.

MALHOTRA, N. K. Pesquisa de marketing: uma orientação aplicada. 3. ed. Porto Alegre: Bookman, 719 p, 2001.

MANOSSO, F. C.; BIZINELLI, C.; GÂNDARA, M. G. A Imagem da Cidade em Fotografias On-line: estudo de caso do site Flickr sobre Curitiba (Paraná, Brasil). Revista Turismo \& Sociedade, v. 6 n. 4, p. 835$860,2013$.

MARUJO, M. N. N. V. A internet como novo meio de comunicação para os destinos turísticos: o caso da Ilha da Madeira. Turismo em Análise, v. 9, n. 1, 2008.

MEDINA, R.; WERNER, M. Internet e Turismo. Disponível em: 〈http://www.univercidade.edu/cursos/ graduacao/tur/pdf/artigos/interneturismo.pdf〉. Acesso em: 17 mai. 2014, 2014.

PARQUE VILA GERMÂNICA. Turismo e Negócios. Disponível em: 〈http://www.parquevilagermanica. com.br/blumenau/turismo-e-negocios》. Acesso em: 02 jun. 2014, 2014.

PÉREZ-NEBRA, A. R.; TORRES, C. V. Medindo a Imagem do Destino Turístico: uma pesquisa baseada na teoria de resposta ao item. Revista RAC, v. 14, n. 1, p. 80-99, 2010.

PERINOTTO, A. R. C. Investigando a comunicação turística de Parnaíba/Piauí - Brasil: internet e redes sociais, descrição e análise. Revista TURyDES, v. 6, n.15, 2013. 
PORTAL BRASIL. Internautas divulgam dicas de turismo em redes sociais. Disponível em: 〈http:// www.brasil.gov.br/turismo/2014/05/internautas-divulgam-dicas-de-turismo-em-redes-sociais〉. Acesso em: 18 mai. 2014, 2014.

PREFEITURA DE BLUMENAU. Perfil da cidade. Disponível em: 〈http://www.blumenau.sc.gov.br/ blumenau/perfildacidade>. Acesso em: 02 jun. 2014, 2014.

REIS, C. Propaganda no rádio: os formatos de anúncio. Blumenau: Edifurb, 119 p, 2008.

SMITH, M.; AMORIM, E.; SOARES, C. O turismo acessível como vantagem competitiva: implicações na imagem do destino turístico. Revista Pasos v. 11, n. 3, p. 97-103, 2013.

TOUR MAG. Tourism, the most popular sector on the Instagram. Disponivel em: 〈http://www.tourmag. com/Tourism-the-most-popular-sector-on-Instagram_a65405.htmlı. Acesso em: 12 mai. 2014, 2014.

VIEIRA, H. F. M. Redes sociais e consumo turístico [trabalho de conclusão de curso]. Niterói: Universidade Federal Fluminense, Curso de Turismo, Faculdade de Administração, Ciências Contábeis e Turismo, 2012. 